\title{
Comparison of the shear bond strengths of conventional mesh bases and sandblasted orthodontic bracket bases
}

\author{
Isabel Cristina Prado Torres \\ Lugato(a) \\ Lilian Maria Brisque Pignatta(b) \\ Flávia de Moraes Arantes ${ }^{(c)}$ \\ Eduardo César Almada Santos ${ }^{(d)}$
}

(a) MSc in Orthodontics; (b) MSc, Graduate Student in Orthodontics; (c) Graduate Student in Orthodontics; (d) Adjunct Professor, Department of Orthodontics - School of Dentistry of Araçatuba, São Paulo State University (UNESP), Araçatuba, SP, Brazil.
Corresponding author:

Eduardo César Almada Santos

Disciplina de Ortodontia, Faculdade de

Odontologia de Araçatuba (UNESP)

Rua José Bonifácio, 1193

Araçatuba - SP - Brazil

CEP: 16015-050

E-mail:almada@foa.unesp.br

Received for publication on May 12, 2008

Accepted for publication on Dec 18, 2008

\begin{abstract}
This study aimed to compare in vitro the shear bond strength between metallic brackets (Abzil) with conventional mesh bases and metallic brackets with bases industrially sandblasted with aluminum oxide using three adhesive systems, in order to assess the influence of sandblasting on adhesiveness and to compare 3 different bonding systems. Two hundred and forty bovine incisors were used and randomly divided into 6 groups (40 teeth in each group), according to the bracket base and to the bonding system. The brackets were direct-bonded in bovine teeth with 3 adhesive systems: System A - conventional Transbond ${ }^{\mathrm{TM}}$ XT (3M Unitek); System B - Transbond ${ }^{\mathrm{TM}}$ Plus Self Etching Primer + Transbond ${ }^{\mathrm{TM}}$ XT (3M - Unitek) and System C - Fuji ORTHO LC resin-reinforced glass ionomer cement in capsules (GC Corp.). Shear bond strength tests were performed 24 hours after bonding, in a DL-3000 universal testing machine (EMIC), using a load cell of $200 \mathrm{kgf}$ and a speed of $1 \mathrm{~mm} / \mathrm{min}$. The results were submitted to statistical analysis and showed no significant difference between conventional and sandblasted bracket bases. However, comparison between the bonding systems presented significantly different results. System A (14.92 MPa) and system C (13.24 MPa) presented statistically greater shear bond strength when compared to system B (10.66 MPa). There was no statistically significant difference between system A and system C.
\end{abstract}

Descriptors: Orthodontics; Shear strength; Orthodontic brackets. 


\section{Introduction and statement of the problem}

The technique of direct orthodontic bonding, the acid conditioning of enamel and the advent of composite resins were important developments that brought definitive changes to orthodontic practice. Historically, Buonocore ${ }^{1}$ (1955) showed that treating the enamel surface with $85 \%$ phosphoric acid for 30 seconds improved the adhesiveness between the enamel surface and the adhesive material. The appearance of white spot lesions around brackets caused by deficient oral hygiene, as well as the possibility of bracket debonding during orthodontic treatment, stimulated the development of new bonding systems that showed greater adhesion force to enamel, associated to fluoride release. ${ }^{2,3}$ With the technological progress of orthodontic materials, there are now bonding systems that present more appropriate adhesiveness to support masticatory and orthodontic forces, and contact with intraoral fluids, allowing tooth movement control in the three planes of space. ${ }^{4}$

In vitro studies on adhesion tests of direct bonding demonstrated that the fracture site in debonding metallic orthodontic brackets is usually located in the resin-bracket interface. ${ }^{5}$ In the wake of this finding, means of increasing adhesion in that area have been searched owing to the influence of mechanical retention. ${ }^{6}$ Several modifications were made in metallic brackets in order to reduce size and improve the bracket base because these variables influence directly the adhesion force. ${ }^{7}$ One of the modifications consists in pre-treating the bracket bases, using different methods: sandblasting, silanation, silica layer application, microetching and adhesive systems application. ${ }^{8,9,10}$

There are several commercial bracket bases available, like those industrially sandblasted with aluminum oxide, that aim at enhancing the resin-bracket adhesion. ${ }^{11,12}$ However, there is still no consensus in the related literature. Siomka, Powers ${ }^{12}$ (1985) and Newman et al. ${ }^{13}$ (1995) found improved shear bond strengths of metallic brackets with sandblasted bases. However, in the studies by Sharma-Sayal et al. ${ }^{14}$ (2003) and Sonis ${ }^{15}$ (1996), also evaluating the effect of sandblasting on bracket bases, this improvement in adhesion was not observed.

Hence, the present study aimed to compare in vitro the shear bond strength of metallic orthodontic brackets with conventional mesh bases and bases industrially sandblasted with aluminum oxide, using three bonding systems, and to assess the influence of sandblasting on adhesiveness, also comparing the three bonding systems.

\section{Material and Methods Material}

Two hundred and forty bovine permanent incisors $^{16,17,18}$ were extracted from animals previously killed in two slaughterhouses (Franco Industrial Foods Ltd. and Friboi Ltd.) for beef commercialization. This research was submitted to the Animal Experimentation Ethics Committee, Brazilian College of Animal Experimentation (COBEA), and an approval certificate was obtained (protocol no. 35/04).

The teeth were stored in a solution of $0.1 \%$ Thymol $^{2,16}$ at room temperature. ${ }^{19}$ The selection criteria excluded teeth with caries and cracks, evaluated by fiber-optic transillumination.

One hundred and twenty stainless steel brackets for maxillary central incisor (Abzil, São José do Rio Preto, SP, Brazil) with conventional mesh bases ${ }^{20}$ (Figure 1A) and 120 similar brackets, however with industrially sandblasted bases ${ }^{12,13,14}$ were used (Figure 1B). The mean base surface area was $13 \mathrm{~mm}^{2}$ for the 2 bracket types.

The orthodontic bonding systems used were: System A - conventional Transbond ${ }^{\mathrm{TM}} \mathrm{XT}^{2,19,21}$ (3M - Unitek, St. Paul, MN, USA); System B - Transbond $^{\mathrm{TM}}$ Plus Self Etching Primer + Transbond ${ }^{\mathrm{TM}}$ $\mathrm{XT}^{4,16,22}$ (3M - Unitek, St. Paul, MN, USA); and System C - Fuji ORTHO LC resin-reinforced glass ionomer cement ${ }^{19,21,23}$ in capsules (GC Corp., Tokyo, Japan) (Table 1).

\section{Methods}

The stages of sample sets preparation are described as follows:

1. Sectioning of the bovine crowns at the crown/ root anatomical limit, in a cutting machine irrigated with distilled water.

2. Flattening of the facial surfaces of the crowns in 

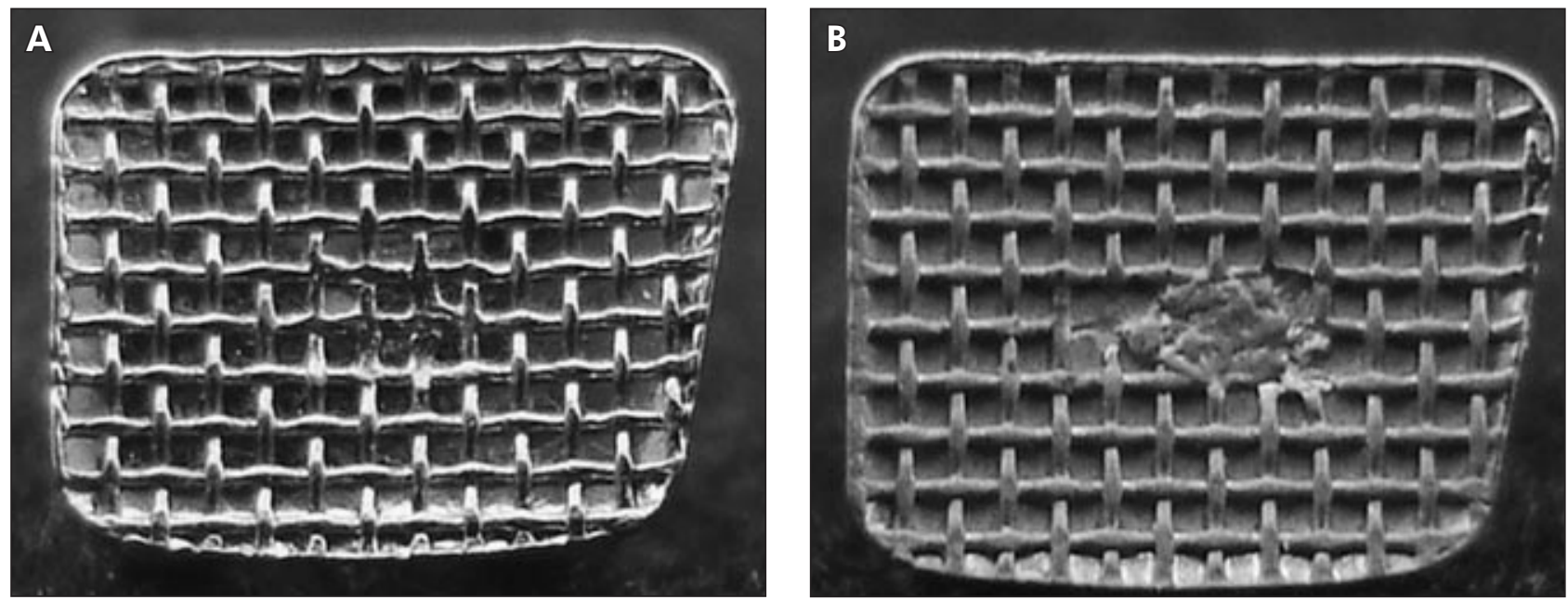

Figure 1 - Abzil Lancer brackets, (A) conventional base and (B) industrially sandblasted base (aluminum oxide).

Table 1 - Bonding systems and respective manufacturers.

\begin{tabular}{l|c|c|c|c}
\hline Bonding System & Adhesive & Conditioner & Adhesive/Primer or Self-Etching Primer & Manufacturer \\
\hline System A (S. A) & Transbond $^{T M}$ XT & 35\% Phosphoric acid gel & Transbond ${ }^{\text {TM Light Cure Adhesive Primer }}$ & $3 M-$ Unitek \\
\hline System B (S. B) & Transbond ${ }^{T M}$ XT & \multicolumn{2}{|c|}{ Transbond ${ }^{T M}$ Plus Self Etching Primer (SEP) } & $3 M-$ Unitek \\
\hline System C (S. C) & $\begin{array}{c}\text { Fuji ORTHO LC Resin-reinforced } \\
\text { glass ionomer cement in capsules }\end{array}$ & $11.5 \%$ polyacrylic acid & & GC Corp. \\
\hline
\end{tabular}

a polishing machine (Politriz APL4, Arotec, Cotia, SP, Brazil), in order to remove enamel irregularities of the facial surface. ${ }^{24}$ The steps taken for facial surface flattening were as follows:

a. Silicon carbide abrasive disks, $\mathrm{SiC} \mathrm{W} / \mathrm{D}$ 203 mm, 8” (Buehler, Lake Bluff, IL, USA) with 320-grit granulation (P400) were coupled to the polishing machine for 2 minutes.

b. 600-grit granulation disks (P1200) were applied for 1 minute until removal of the irregularities present on the facial surface of the crowns.

c. Then, the crowns were polished for $30 \mathrm{sec}-$ onds with polishing fabrics Texmet 1000, 8" (Buehler, Lake Bluff, IL, USA) and aqueous diamond suspension $6 \mu$ - Metadi Supreme $240 \mathrm{ml}$ (Buehler, Lake Bluff, IL, USA).

3. Positioning of the crowns with the flattened facial surface parallel to the vertical stem of the surveyor with pink wax number 7 (Figure 2). The crowns were embedded $0.5 \mathrm{~cm}$ in the rollers so that the facial surfaces remained perpendicu- lar to the rollers and parallel to the force applied during the shear strength tests.

4. Embedding of the crowns in the rollers with autopolymerizing acrylic resin.

The bonding systems were used according to each manufacturer's recommendations, and the bonding procedures were performed by a single operator (I.T.L.). ${ }^{16,21}$ After tooth prophylaxis and enamel conditioning, the adhesive paste was applied to the whole extension of the bracket bases. Brackets were positioned on the flat facial surface and a seating pressure of 10 ounces for 10 seconds was applied in the middle of the bracket by a gauge (Dontrix E.T.M Corporation, Monrovia, California, USA $)^{25}$ with the objective of draining excess bonding material. ${ }^{2,4}$ Just before the polymerization procedure, all excess was removed from the edges of the brackets. The 240 sample sets were divided into 6 groups of 40 (Table 2), according to the bracket base and to the bonding system.

The shear bond strength tests were performed 24 hours after bonding. ${ }^{26,27}$ During this period, the 
sample sets were maintained in deionized water. ${ }^{2,18}$ The destructive tests were performed in a DL 3000 universal testing machine (EMIC Equipamentos e Sistemas de Ensaio Ltda., São José dos Pinhais, PR, Brazil) using a load cell of $200 \mathrm{kgf}$ and speed of $1 \mathrm{~mm} / \mathrm{min}^{19,26}$ in the incisocervical direction (Figure 3). A force applier tip was especially constructed for this research, so the force was applied as close as possible to the bracket-tooth interface. The sample sets were fastened in the universal machine by a metallic support coupled to an adjustable base. The values of maximum load for the debonding of each bracket were registered in kilogram-force per square millimeter $\left(\mathrm{kgf} / \mathrm{mm}^{2}\right)$ and converted to megapascals $(\mathrm{MPa})$.

\section{Results}

The descriptive statistics of the shear bond strength tests (minimum, maximum, mean and standard deviation values) of all groups are described in Table 3 .

The data of each group were submitted to statistical analysis, performed by 2-way ANOVA (Table 4). No statistically significant difference at a 5\% level of significance was observed between conventional mesh bases and sandblasted bases, but a significant difference was found between the bonding systems.

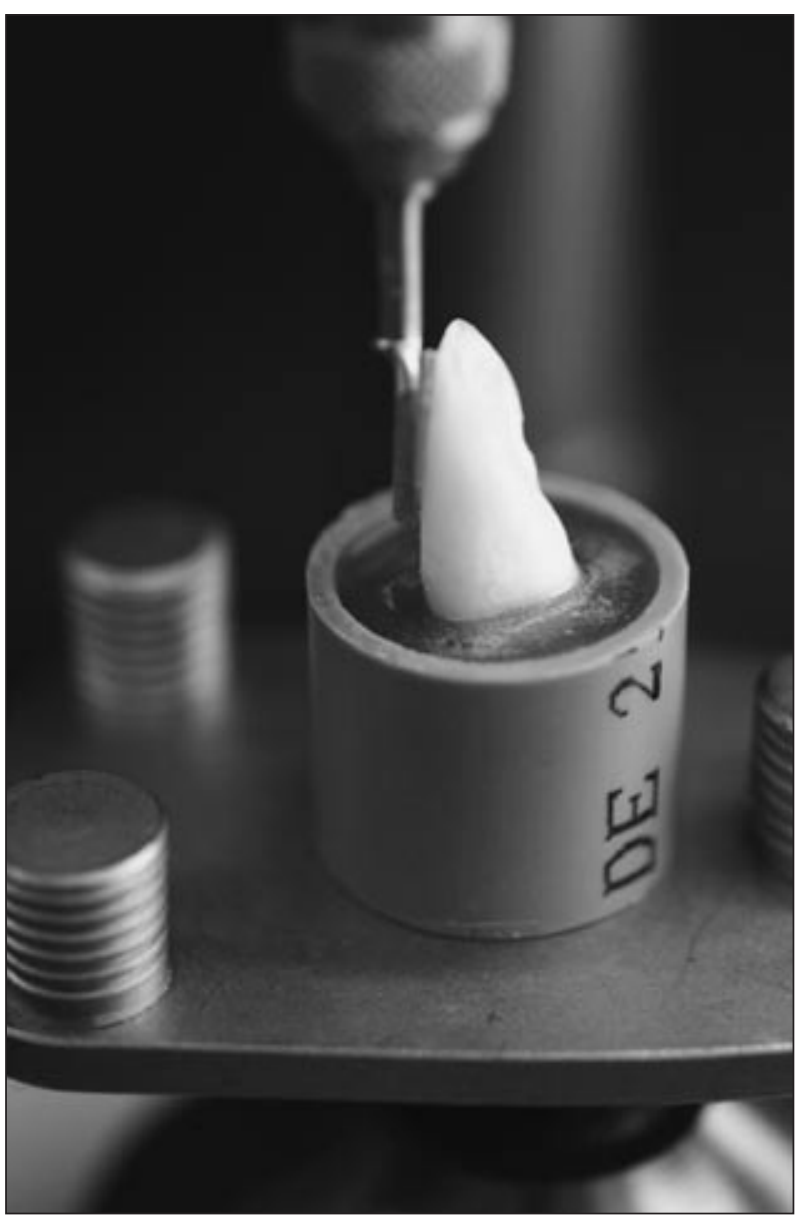

Figure 2 - Use of the surveyor (Bio Art) to prepare the test specimens.

Table 2 - Study groups according to the bracket base and to the bonding system.

\begin{tabular}{c|c|c|c|c|c}
\hline Group & $\mathrm{N}$ & Bracket base & Manufacturer & Bonding system & Manufacturer \\
\hline 1 (control) & 40 & conventional & AbZIL & (S.A) & $3 M-$ Unitek \\
\hline 2 & 40 & sandblasted & AbZIL & (S.A) & $3 M-$ Unitek \\
\hline 3 & 40 & conventional & AbZIL & (S.B) & $3 M-$ Unitek \\
\hline 4 & 40 & sandblasted & AbZIL & (S.B) & $3 M-$ Unitek \\
\hline 5 & 40 & conventional & AbZIL & (S.C) & GC Corp. \\
\hline 6 & 40 & sandblasted & AbZIL & (S.C) & GC Corp. \\
\hline
\end{tabular}

Table 3 - Descriptive statistics of the shear bond strength tests for all groups (minimum, maximum, mean and standard deviation values, in $\mathrm{MPa})$.

\begin{tabular}{c|c|c|c|c|c|c}
\hline & Group 1 & Group 2 & Group 3 & Group 4 & Group 5 & Group 6 \\
\hline Minimum & 0.43 & 2.38 & 1.41 & 0.34 & 1.66 & 1.68 \\
\hline Maximum & 26.65 & 30.67 & 17.93 & 23.43 & 26.24 & 25.65 \\
\hline Mean & 13.51 & 16.32 & 10.84 & 10.49 & 13.46 & 13.02 \\
\hline sd & 6.17 & 6.85 & 4.35 & 5.11 & 6.75 & 6.17 \\
\hline
\end{tabular}


Table 4 - Results of 2-way ANOVA.

\begin{tabular}{c|c|c|c|c|c|c}
\hline Variables (Effect) & $d f(E f f e c t)$ & RMS (Effect) & df (Error) & RMS (Error) & $F$ & $p$ \\
\hline Bonding system & $2^{*}$ & $367.2006^{*}$ & $234^{*}$ & $35.65199^{*}$ & $10.29959^{*}$ & $0.000052^{*}$ \\
\hline Bracket bases & 1 & 27.0212 & 234 & 35.65199 & 0.75791 & $0.384874^{\text {ns }}$ \\
\hline Interaction & 2 & 68.2066 & 234 & 35.65199 & 1.91312 & $0.149921^{\text {ns }}$ \\
\hline
\end{tabular}

$*$ = statistically significant difference $(p<0.05) . n s=$ not significant $(p>0.05)$. df: degrees of freedom; RMS: root mean square.

Table 5 - Results of the Tukey tests for individual comparisons between bonding systems. Mean values are shown in parenthesis ( $\mathrm{MPa}$ ).

\begin{tabular}{|c|c|c|c|}
\hline \multicolumn{3}{|c|}{ Comparisons } & \multirow{2}{*}{$\begin{array}{c}\mathrm{p} \\
0.00004^{*}\end{array}$} \\
\hline $\begin{array}{c}\text { Transbond }{ }^{T M} X T \text { conventional } \\
\qquad(14.92)\end{array}$ & $\mathrm{x}$ & $\begin{array}{l}\text { Transbond }{ }^{T M} \text { XT conventional + } \\
\text { Transbond }^{\text {TM }} \text { Plus SEP }(10.66)\end{array}$ & \\
\hline $\begin{array}{c}\text { Transbond }^{\top M} \mathrm{XT} \text { conventional I } \\
\text { (14.92) }\end{array}$ & $x$ & Fuji ORTHO LC (13.24) & $0.17870^{\text {ns }}$ \\
\hline $\begin{array}{l}\text { Transbond }^{\mathrm{TM}} \text { XT conventional + } \\
\text { Transbond }{ }^{\mathrm{TM}} \text { Plus SEP }(10.66)\end{array}$ & $x$ & Fuji ORTHO LC (13.24) & $0.01735^{*}$ \\
\hline
\end{tabular}

Tukey tests were applied for individual comparisons between the bonding systems (Table 5).

The behavior of the bonding systems in relation to the different bracket bases is shown in Graph 1. It could be observed that system A presented the greatest shear bond strength when sandblasted bracket bases were used.

\section{Discussion}

A lack of standardization in the methodology of in vitro shear bond strength tests in Orthodontics is evidenced in the literature, ${ }^{28}$ hindering comparisons of the results obtained by different studies.

Bovine teeth were chosen for bracket bonding because they are easily obtained, they are similar to each other and because bovine enamel is similar to human enamel. These factors allow the conducting of reliable shear bond strength in vitro studies, thus justifying the increasing use of bovine teeth in orthodontic research. ${ }^{17,28}$ Oesterle et al. ${ }^{17}$ (1998) observed that the bovine enamel from deciduous and permanent teeth present respectively $21 \%$ and $44 \%$ less shear bond strength than human enamel. ${ }^{17}$

The removal of the irregularities of the facial surfaces of the bovine teeth used in this study was done in order to minimize bias in the results and to standardize the method. ${ }^{24}$ Shear bond strength tests were used since they apply forces similar to those that frequently promote failures in bracket bonding in orthodontic practice, ${ }^{27}$ in spite of the difficulty of in vitro reproduction. ${ }^{26}$

Bracket base treatment (sandblasting) to increase shear bond strength was suggested in 1971 by Mizrahi and Smith. ${ }^{6}$ After identifying that the failure site was more frequently found in the adhesive-bracket interface than in the tooth-adhesive interface, ${ }^{5}$ the number of studies attempting to find an ideal shear bond strength for this interface increased, thus emphasizing the importance of bracket bases. ${ }^{5,14}$ Aluminum oxide sandblasting, as well as other types of bracket base treatment, promotes the removal of oxidizers, pollutants and increases the wrinkles and porosity of the bracket bases, thus increasing the energy of the bonding surface and area. ${ }^{13}$ Thus, the expectation would be that treatments of the bracket bases could increase the shear bond strength in the adhesive-bracket interface. This, however, is not a consensus in the literature.

Siomka, Powers ${ }^{12}$ (1985) and Newman et al. ${ }^{13}$ (1995) suggested that bracket base treatments could improve bond strength when using the following techniques: sandblasting, silanation and silica layer application. However, some results mentioned in the literature ${ }^{13,15}$ diverge from those found in the present study, as the industrial sandblasting with aluminum oxide did not increase the shear bond strength in groups 4 and 6. An increase was observed only in Group 2 (sandblasted bracket bases and bonding 


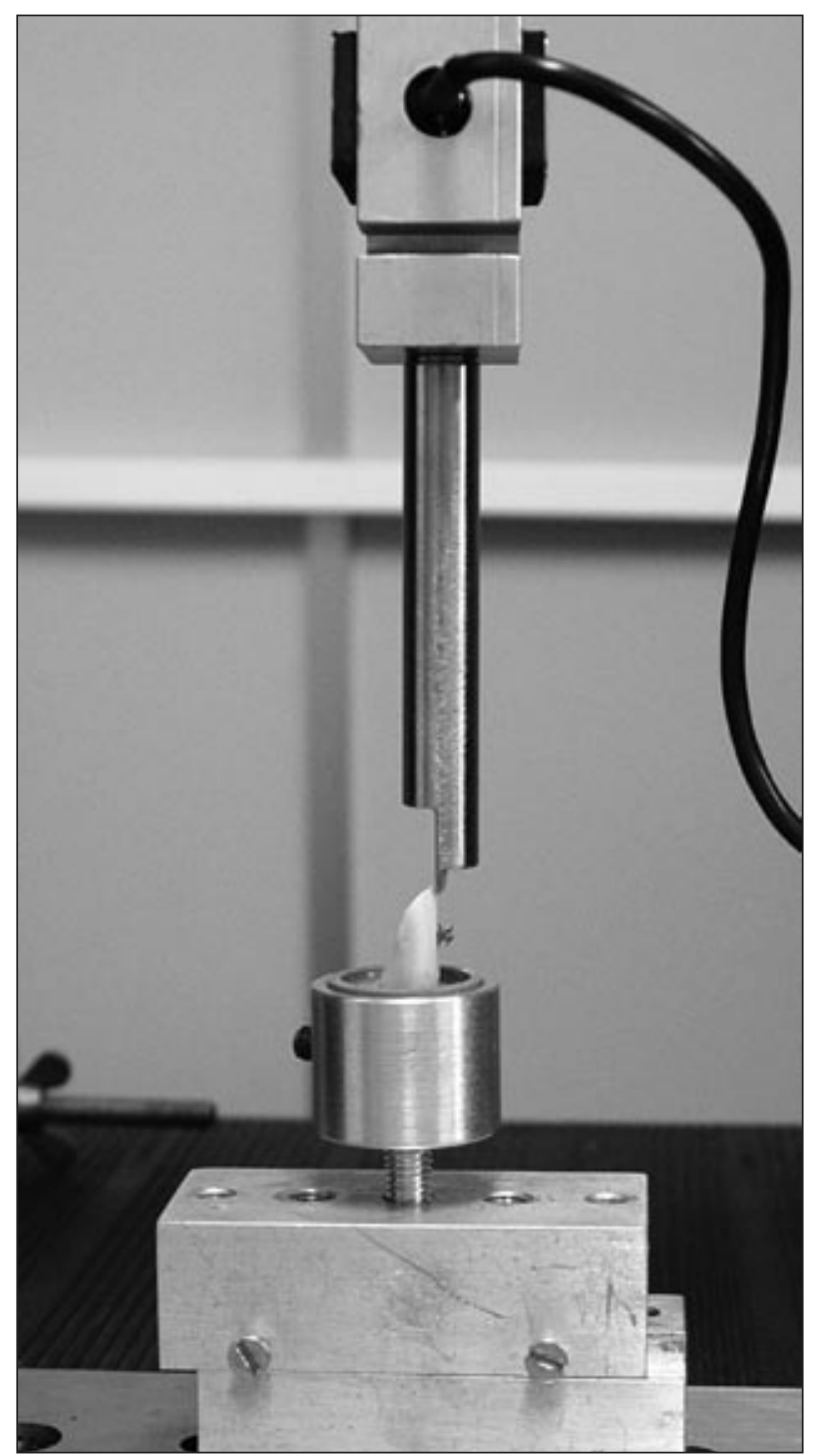

Figure 3 - Illustration of the destructive test: the load cell of $200 \mathrm{kgf}$, the force applier tip and the metallic support under an adjustable base.

system A) (Table 3). However, after the statistical analysis was performed by 2 -way ANOVA at a $5 \%$ level of significance, the results for all groups did not present statistically significant differences, corroborating the studies by Sharma-Sayal et al. ${ }^{14}$ (2003) and Sonis ${ }^{15}$ (1996), who evaluated metallic brackets with sandblasted and non sandblasted bases and did not find differences between these two types of bracket bases. This difference in results can be due to the several sandblasting methods, as well as to variations in mesh base size and configurations. ${ }^{14,15}$ However, in the present study the industrial sand-

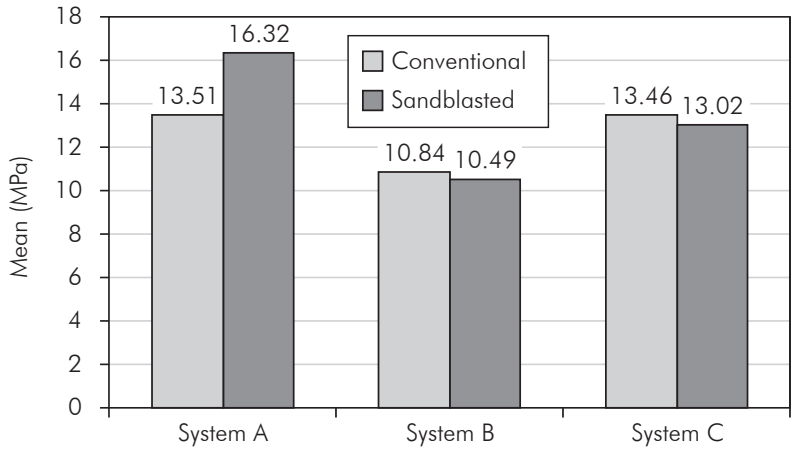

Graph 1 - Behavior of the bonding systems in relation to the different bracket bases.

blasting with aluminum oxide did not influence the shear bond strength and adhesiveness results for any of the bonding systems.

Although no statistically significant differences were found between the bracket bases, as shown in Table 4, these differences were observed in the results of the 2-way ANOVA between the bonding systems $(\mathrm{p}<0.05)$. Tukey tests at a $5 \%$ level of significance were performed for individual comparisons between the bonding systems, and the results showed that system C $(13.24 \mathrm{MPa})$ did not differ significantly from system A (14.92 MPa), which agrees with the results obtained by Meehan et al. ${ }^{29}$ (1999). However, those two systems presented significantly greater results when compared to system B (10.66 MPa).

The lower shear bond strength values found for the groups bonded with system $\mathrm{B}$ when compared to systems $\mathrm{A}$ and $\mathrm{C}$ can be associated to the chemical composition and to the method of application of the Transbond ${ }^{\mathrm{TM}}$ Plus Self Etching Primer. ${ }^{25}$ Regarding the results of the Fuji ORTHO LC resin-reinforced glass ionomer cement, the shear bond strength and adhesion values proved to be acceptable, corroborating the studies by Lippitz et al. ${ }^{30}$ (1998), Millett et al. ${ }^{9}$ (1993) and the study conducted by Cacciafesta et al. ${ }^{21}$ (2003), in which the shear bond strength of this cement was tested using the same methodology as in the present study, and presented values of $13.09 \mathrm{MPa}$, which was similar to our result $(13.24 \mathrm{MPa})$. Considering that a shear bond strength value of $7 \mathrm{MPa}$ is clinically acceptable, ${ }^{30}$ system A obtained an excellent value of shear bond 
strength (14.92 MPa).

\section{Conclusions}

This in vitro comparison between metallic brackets with conventional mesh bases and metallic brackets with bases industrially sandblasted with aluminum oxide did not show significant differences in the shear bond strength tests. It could be conclud-

\section{References}

1. Buonocore MG. A simple method of increasing the adhesion of acrylic filling materials to enamel surfaces. J Dent Res. 1955;34(6):849-53.

2. Bishara SE, Ajlouni R, Laffoon JF, Warren JJ. Effect of a fluoride-releasing self-etch acidic primer on the shear bond strength of orthodontic brackets. Angle Orthod. 2002;72(3):199202.

3. Cacciafesta V, Jost-Brinkmann PG, Süssenberger U, Miethke R. Effects of saliva and water contamination on the enamel shear bond strength of a light-cured glass ionomer cement. Am J Orthod Dentofacial Orthop. 1998;113(4):402-7.

4. Bishara SE, Oonsombat C, Ajlouni R, Laffoon JF. Comparison of the shear bond strength of 2 self-etch primer/adhesive systems. Am J Orthod Dentofacial Orthop. 2004;125(3):34850.

5. Keizer S, Ten Cate JM, Arends J. Direct bonding of orthodontic brackets. Am J Orthod. 1976;69(3):318-27.

6. Mizrahi E, Smith DC. Direct attachment of orthodontic brackets to dental enamel. Brit Dent J. 1971;130(4):392-6.

7. Wang WN, Li CH, Chou TH, Wang DDH, Lin LH, Lin CT. Bond strength of various bracket base designs. Am J Orthod Dentofacial Orthop. 2004;125(1):65-70.

8. Powers JM, Kim HB, Turner D. Orthodontic adhesives and bond strength testing. Semin Orthod. 1997;3(3):147-56.

9. Millett D, McCabe JF, Gordon PH. The role of sandblasting on the retention of metallic brackets applied with glass ionomer cement. Br J Orthod. 1993;20(2):117-22.

10. Wright WL, Powers JM. In vitro tensile bond strength of reconditioned brackets. Am J Orthod. 1985;87(3):247-52.

11. Newman GV, Sun BC, Ozsoylu SA, Newman RA. Update on bonding brackets: An in vitro survey. J Clin Orthod. 1994;28(7):396-412.

12. Siomka LV, Powers JM. In vitro bond strength of treated direct-bonding metal bases. Am J Orthod. 1985;88(2):133-6.

13. Newman GV, Newman RA, Sun BI, Ha JL, Ozsoylu SA. Adhesion promoters, their effect on the bond strength of metal brackets. Am J Orthod Dentofacial Orthop. 1995;108(3):23741.

14. Sharma-Sayal SK, Rossouw PE, Kulkarni GV, Titley KC. The influence of orthodontic bracket base design on shear bond ed that the sandblasting of the bracket bases did not influence adhesiveness. A comparison between the bonding systems demonstrated statistically significant differences. System A (14.92 MPa) and system $\mathrm{C}(13.24 \mathrm{MPa})$ presented significantly higher values when compared to system B (10.66 MPa). However, systems A and C did not present statistically significant differences.

strength. Am J Orthod Dentofacial Orthop. 2003;124(1):74 82.

15. Sonis A. Air abrasion of failed bonded metal brackets: a study of shear bond strength and surface characteristics as determined by scanning electron microscopy. Am J Orthod Dentofacial Orthop. 1996;110(1):96-8.

16. Cacciafesta V, Sfondrini MF, Scribante A, De Angelis M, Klersy C. Effect of water and saliva contamination on shear bond strength of brackets bonded with conventional, hydrophilic and self-etching primers. Am J Orthod Dentofacial Orthop. 2003;123(6):633-40.

17. Oesterle LJ, Shellhart WC, Belanger GK. The use of bovine enamel in bonding studies. Am J Orthod Dentofacial Orthop. 1998;114(5):514-9.

18. Yamada R, Hayakawa T, Kasai K. Effect of using self-etching primer for bonding orthodontic brackets. Angle Orthod. 2002;72(6):558-64.

19. Owens Jr SE, Miller BH. A comparison of shear bond strengths of three visible light-cured orthodontic adhesives. Angle Orthod. 2000;70(5):352-6.

20. Matasa CG. Direct bonding metallic brackets: where are they heading? Am J Orthod Dentofacial Orthop. 1992;102(6):55260.

21. Cacciafesta V, Sfondrini MF, Baluga L, Scribante A, Klersy C. Use of a self-etching primer in combination with a resin-modified glass ionomer: effect of water and saliva contamination on shear bond strength. Am J Orthod Dentofacial Orthop. 2003;124(4):420-6.

22. Bishara SE, Oonsombat C, Soliman MMA, Warren JJ, Laffoon JF, Ajlouni R. Comparison of bonding time and shear bond strength between a conventional and a new integrated bonding system. Angle Orthod. 2005;75(2):237-42.

23. Larmour CJ, Stirrups DR. An ex vivo assessment of a resinmodified glass ionomer cement in relation to bonding technique. J Orthod. 2001;28(1):207-10.

24. Arnold RW, Combe EC, Warford Jr JH. Bonding of stainless steel brackets to enamel with a new self-etching primer. Am J Orthod Dentofacial Orthop. 2002;122(3):274-6. 
25. Chamda RA, Stein E. Time-related bond strengths of lightcured and chemically cured bonding systems: an in vitro study. Am J Orthod Dentofacial Orthop. 1996;110(4):378-82.

26. Katona TR. The effects of load location and misalignment on shear/peel testing of direct bonded orthodontic brackets - a finite element model. Am J Orthod Dentofacial Orthop. 1994;106(4):395-402.

27. Millet DT, McCabe JF. Orthodontic bonding with glass ionomer cement: a review. Eur J Orthod. 1996;18(4):385-99.
28. Fox NA, McCabe JF, Buckley JG. A critic of bond strength testing in orthodontics. Br J Orthod. 1994;21(1):33-43.

29. Meehan MP, Foley TF, Mamandras AH. A comparison of the shear bond strengths of two glass ionomer cements. Am J Orthod Dentofacial Orthop. 1999;115(2):125-32.

30. Lippitz SJ, Staley RN, Jakobsen JR. In vitro study of 24-hour and 30-day shear bond strengths of three resin-glass ionomer cements used to bond orthodontic brackets. Am J Orthod Dentofacial Orthop. 1998;113(6):620-24. 